\title{
Genetic merit for fertility traits in Holstein cows: II. Ovarian follicular and corpus luteum dynamics, reproductive hormones, and estrus behavior
}

\author{
S. B. Cummins, ${ }^{\star} \dagger$ P. Lonergan, $†$ A. C. O. Evans, $\nmid$ and S. T. Butler ${ }^{* 1}$ \\ *Animal and Grassland Research and Innovation Centre, Teagasc, Moorepark, Fermoy, Co. Cork, Ireland \\ †School of Agriculture and Food Science, University College Dublin, Belfield, Dublin 4, Ireland
}

\begin{abstract}
The objective of this study was to characterize the estrous cycle of cows with similar proportions of Holstein genetics, similar genetic merit for milk production traits, but with good (Fert+) or poor (Fert-) genetic merit for fertility traits. In total, 37 lactating cows were enrolled on a protocol to synchronize estrus. Nineteen Fert+ and 12 Fert- cows that successfully ovulated a dominant follicle and established a corpus luteum underwent daily transrectal ultrasonography. Blood sampling was carried out at 8 -h intervals from d 0 to 6 and from d 15 to ovulation, and once daily from d 7 to 15 . Blood samples were analyzed for progesterone, estradiol, follicle stimulating hormone, and luteinizing hormone. Estrus behavior was recorded using neck activity collars and mounting pads. The Fert+ cows tended to have fewer follicular waves (2.2 vs. 2.7) and had a shorter estrous cycle (21.0 vs. $25.1 \mathrm{~d})$ than Fertcows. We observed no effect of genotype on day of firstwave emergence or day of first-wave dominant follicle peak diameter, but the peak diameter of the first-wave dominant follicle tended to be larger in Fert- cows. During the first $13 \mathrm{~d}$ of the cycle, Fert+ cows developed a corpus luteum that was 16\% larger than that in Fert- cows. Circulating progesterone concentrations were $34 \%$ greater in Fert+ than in Fert- cows (5.15 vs. $3.84 \mathrm{ng} / \mathrm{mL}$, respectively) from d 5 to 13 . During the final follicular wave, the interval from preovulatory follicle emergence to ovulation and the interval from preovulatory follicle dominance to ovulation were similar in both genotypes. Maximum preovulatory follicle diameter was larger in Fert+ than Fert- cows (17.9 vs. $16.8 \mathrm{~mm}$, respectively); however, circulating concentrations of estradiol were not different between genotypes. A greater proportion of Fert- cows ovulated to a silent heat than Fert+ cows (22 vs. 2\%, respectively). Of cows that showed behavioral estrus, Fert+ cows had $41 \%$
\end{abstract}

Received September 26, 2011.

Accepted February 27, 2012.

${ }^{1}$ Corresponding author: stephen.butler@teagasc.ie greater mean activity count; however, no difference was seen in mounting behavior between genotypes. These results demonstrate, for the first time, that genetic merit for fertility has pronounced effects on corpus luteum development, progesterone concentration, preovulatory follicle diameter, and behavioral estrus.

Key words: genetic merit for fertility, reproduction, estrous cycle, progesterone

\section{INTRODUCTION}

Reproductive efficiency in Holstein dairy cows has declined over the last $50 \mathrm{yr}$ in Ireland (Evans et al., 2006) and worldwide (Royal et al., 2000; Washburn et al., 2002). Despite intensive research, the precise mechanisms contributing to this decline in dairy cow fertility remains poorly understood. Ovarian activity is under the control of the hypothalamic-pituitary-ovarian-uterine axis and is central to reproductive success (Robinson et al., 2008). Increased incidence of ovarian abnormalities such as prolonged postpartum anestrus, cystic ovarian disease (Wiltbank et al., 2002), reduced estrus behavior (Dransfield et al., 1998), and reduced circulating concentrations of progesterone (P4) and estradiol (E2; Wiltbank et al., 2001, 2006) have all been cited as potential factors associated with declining reproductive performance in high-producing dairy cows.

Fertility performance of nonlactating Holstein heifers has remained relatively static during the last $50 \mathrm{yr}$ (Pursley et al., 1997; Sartori et al., 2002). The decline in fertility in lactating cows, therefore, appears to be a result of the energetic burden associated with initiation and maintenance of lactation (Butler and Smith, 1989). Previous studies have used this high fertility (nonlactating heifer or cow) versus low fertility (lactating cow) animal model to determine characteristics of the estrous cycle that contribute to poor fertility in lactating dairy cows (De la Sota et al., 1993; Sartori, 2000; Sartori et al., 2004; Wolfenson et al., 2004). A study comparing cows of high or low genetic merit for milk production demonstrated a negative association between circulating $\mathrm{P} 4$ concentration and genetic merit for milk production (Lucy and Crooker, 2001). These 
studies have provided valuable insight into the effects of lactation on characteristics of the estrous cycle, but they are confounded by effects of age, nutrition, energy status, BCS, uterine environment, and other factors (Wolfenson et al., 2004).

We have recently shown that reproductive performance in pasture-based production systems is more dependent on genetic merit for fertility traits than genotypic or phenotypic milk production (Cummins et al., 2012). The underlying physiological differences, however, between cows with good (Fert+) and poor (Fert-) genetic merit for fertility traits that are responsible for the observed differences in phenotypic fertility performance remain unknown. Therefore, the aim of this study was to characterize dynamics of ovarian follicle and corpus luteum (CL) development in Fert+ and Fert- cows. Specifically, we tested the hypothesis that genetic merit for fertility traits would affect ovarian follicular waves, preovulatory follicle development, CL volume, circulating concentrations of steroids and gonadotropins, and estrus behavior.

\section{MATERIALS AND METHODS}

\section{Herd Establishment}

The Economic Breeding Index is a multi-trait profit index introduced in 2001, and it has evolved to include 6 sub-indices (relative emphasis in parentheses); milk production (38.1\%), fertility/survival (34.8\%), calving performance $(10.3 \%)$, beef carcass $(7.2 \%)$, maintenance (6.1\%), and health (3.6\%) (http://www.icbf.com). The fertility sub-index is composed of 2 traits: calving interval $(23.2 \%)$ and survival (11.5\%). Good genetic merit for fertility traits requires negative EBV for calving interval and positive EBV for survival. The establish- ment of the herd was carried out during autumn 2007 using official dairy evaluations published by the Irish Cattle Breeding Federation and was outlined in detail by Cummins et al. (2012). The national dairy cattle database was screened for nulliparous spring-calving heifers. Strict restrictions were placed on EBV for milk production (between $+200 \mathrm{~kg}$ and $+900 \mathrm{~kg}$ ) and proportion of Holstein genes $(>75 \%)$. Within this population, heifers with extreme positive (poor fertility) and negative (good fertility) EBV for calving interval were identified. Poor fertility (Fert-) heifers were restricted to animals in which sire and maternal grandsire had positive EBV for calving interval. Conversely, good fertility (Fert + ) heifers were restricted to animals in which the sire and maternal grandsire had negative EBV for calving interval. Nulliparous Fert+ and Fert- cows were purchased in 2008 and $2009(\mathrm{n}=28$ of each genotype). Animals that calved between Jan 11 and April 10,2009 , were enrolled in the current study $(\mathrm{n}=37)$; 21 were Fert+ (6 first lactation and 15 second lactation) and 16 were Fert- ( 8 first lactation and 8 second lactation). At the time of initiating the synchronization protocol, the average DIM (range in parentheses) of the Fert+ and Fert- cows was $95 \mathrm{~d}(44$ to $113 \mathrm{~d})$ and $81 \mathrm{~d}$ (37 to 113 d), respectively. The EBV of these cows are summarized in Table 1. Within the Irish national herd, these animals were representative of the top quartile in genetic merit for milk production, whereas the Fert+ and Fert-groups represented the top 20\% and bottom $5 \%$ for calving interval, respectively.

\section{Management System}

For the duration of the study, cows were kept on a clean stand-off, wood-chipped pad (Hickey et al., 2003)

Table 1. The mean (SD in parentheses) $\mathrm{EBV}^{1}$ for cows with good (Fert+) and poor (Fert-) genetic merit for fertility traits for milk production, survival, and calving interval

\begin{tabular}{lcc}
\hline & \multicolumn{2}{c}{ Genotype } \\
\cline { 2 - 3 } Item & Fert+ & Fert- \\
\hline Animals (no.) & 21 & 16 \\
NAHF $^{2}(\%)$ & $91.2(6.45)$ & $93.2(6.96)$ \\
Milk (kg) & $455.5(133.9)$ & $433.2(119.9)$ \\
Fat (kg) & $21.5(7.37)$ & $17.5(6.59)$ \\
Protein (kg) & $18.3(5.43)$ & $17.1(5.01)$ \\
Fat (g/kg) & $0.085(0.117)$ & $0.025(0.119)$ \\
Protein (g/kg) & $0.069(0.049)$ & $0.06(0.069)$ \\
Survival (\%) & $3.12(0.80)$ & $-0.24(1.22)$ \\
Calving interval (d) & $-6.42(1.44)$ & $5.49(2.22)$ \\
Sire calving interval (d) & $-9.14(3.77)$ & $6.69(2.17)$ \\
Maternal grandsire calving interval (d) & $-5.14(2.20)$ & $7.30(4.59)$ \\
\hline${ }^{1}$ All PTA were obtained from the autumn 2008 and autumn 2007 official dairy evaluations published by the \\
Irish Cattle Breeding Federation and multiplied by 2 to convert to EBV.
\end{tabular}


and given full-time access to grass silage. Cows were individually fed $5 \mathrm{~kg}$ of concentrate per day during the a.m. and p.m. milkings. The concentrate composition on a fresh weight basis (relative proportion in parentheses) was citrus pulp (47\%), corn gluten (47\%), soybean oil $(3 \%)$, and minerals-vitamins $(3 \%)$. The chemical composition of grass silage and concentrate is summarized in Table 2.

Milk yield was recorded at each milking using electronic milk meters (Dairymaster, Causeway, Co. Kerry, Ireland). Milk composition (fat, protein, and lactose) was determined weekly from successive evening and morning samples by near-infrared reflectance spectroscopy (FT6000 Milkoscan instrument, Foss Electric, Hillerød, Denmark). Cow BCS was measured on d 21 of the cycle. Mean calving dates were February 11 (SD $\pm 21.2 \mathrm{~d})$ and February $25(\mathrm{SD} \pm 24.6 \mathrm{~d})$ for the Fert+ and Fert-cows, respectively.

\section{Estrous Synchronization}

Transrectal ultrasonography was carried out on all cows to determine utero-ovarian status $(7.5-\mathrm{MHz}$ transrectal transducer, Aloka SSD-900, Aloka Ltd., Tokyo, Japan). Cows that were diagnosed as anestrus or as having a uterine infection were removed from the study (2 cows). The remaining 37 cows were enrolled on a standard protocol to synchronize estrus (Figure 1). On $\mathrm{d}-10$, each cow was administered an i.m. injection of a GnRH agonist containing $10 \mu \mathrm{g}$ of buserelin (Receptal; Intervet Ireland, Dublin, Ireland), and a controlled
Table 2. The mean (SD in parentheses) chemical composition (g/ $\mathrm{kg}$ of DM) of grass silage and concentrate supplement fed during the experimental period

\begin{tabular}{lcc}
\hline Item & Grass silage & Concentrate \\
\hline ADF & $359.1(17.4)$ & - \\
CP & $148.0(20.0)$ & $147.3(18.3)$ \\
NDF & $521.8(27.2)$ & $316.3(93.0)$ \\
Ash & $93.4(12.3)$ & $96.3(4.8)$ \\
Crude fiber & - & $102.5(2.03)$ \\
\hline
\end{tabular}

internal drug release device (CIDR, Pfizer Ireland, Dublin, Ireland) containing $1.38 \mathrm{~g}$ of $\mathrm{P} 4$ was inserted per vaginum. On $\mathrm{d}-3$, each cow was administered an i.m. injection of $\mathrm{PGF}_{2 \alpha}$ containing $25 \mathrm{mg}$ of dinoprost tromethamine (Lutalyse, Pfizer Ireland). The CIDR devices were removed on $\mathrm{d}-2$. Transrectal ultrasonography commenced on the day of expected estrus. Animals that failed to ovulate the DF (4 Fert- cows) or that developed a cystic ovarian structure (2 Fert+ cows) were removed from the study. The remaining 19 Fert+ and 12 Fert- cows that were successfully synchronized underwent frequent transrectal ultrasonography and blood sampling for one complete estrous cycle (Figure 1).

\section{Transrectal Ultrasonography and Estrus Behavior Measurements}

Transrectal ultrasound was carried out daily. For all ovarian structures $\geq 5 \mathrm{~mm}$, the largest image was captured, and cross-section measurements of height

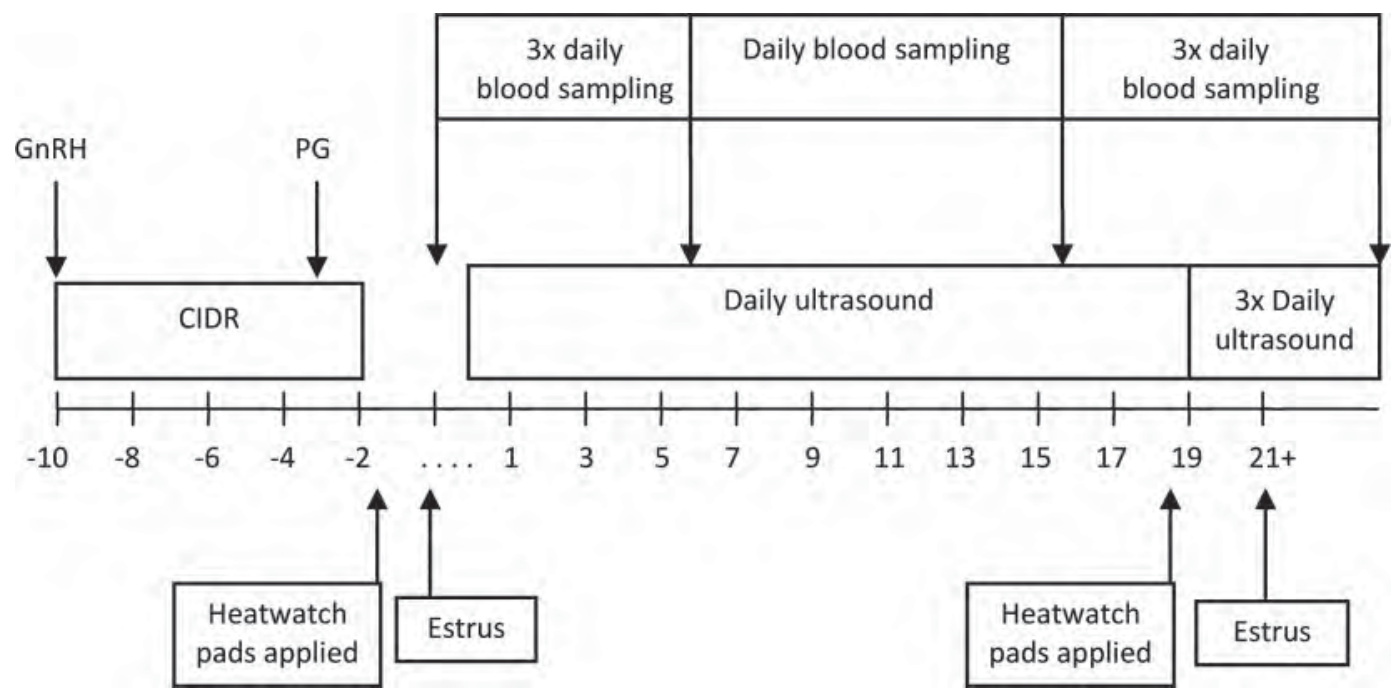

Figure 1. Synchronization protocol, blood sampling, and ultrasound frequency for one complete estrous cycle relative to day of ovulation $(\mathrm{d} 0) . \mathrm{CIDR}=$ intravaginal progesterone $(\mathrm{P} 4)$-releasing device containing $1.38 \mathrm{~g}$ of $\mathrm{P} 4 ; \mathrm{GnRH}=\mathrm{GnRH}$ agonist injections contained $10 \mu \mathrm{g}$ of buserelin; $\mathrm{PG}=$ prostaglandin $\mathrm{F}_{2 \alpha}$ analog; $\mathrm{OV}=$ ovulation. 
and width were recorded on ovarian charts. Ovulation was deemed to have occurred when a large dominant follicle (DF) could no longer be visualized and a luteal structure subsequently formed. This was set as d 0 of the estrous cycle. Starting $18 \mathrm{~h}$ after commencement of estrus behavior at the spontaneous heat at the end of the estrous cycle, ultrasonography was carried out at 8-h intervals to determine the time of ovulation. Follicular data was combined for both ovaries. Follicle diameter was calculated as (length + width) $/ 2$. The day of wave emergence was determined as the day when the retrospectively determined DF was $\leq 5 \mathrm{~mm}$. The timing of follicle dominance was defined as the beginning of the greatest differences in growth rates between the 2 largest follicles (Ginther et al., 1997). The volume of a CL was calculated with the formula $\mathrm{V}=4 / 3 \times \pi$ $\times$ radius $^{3}$; if present, the volume of luteal cavities was removed from the final CL volume figure.

Cow activity and mounting data were recorded during synchronized and spontaneous estrus using radiotelemetry transmitters (DDx HeatWatch, Denver, CO) and activity collars (Moomonitor, Dairymaster). HeatWatch pads were applied according to the manufacturer's instructions $2 \mathrm{~d}$ before expected estrus. Activity collars were applied for the duration of the trial, and raw activity data, averaged at 6 -h intervals, were used as the index of cow activity during spontaneous estrus. Cows required $>2$ standing mounts to be deemed in estrus. The commencement of estrus was defined as the first standing mount where the second standing mount was followed within a 2-h period; similarly, the end of estrus was defined as the last standing mount where the previous mount was less than $2 \mathrm{~h}$ prior. The duration of estrus was determined for all cows that exhibited standing estrus and was calculated as the interval from first mount to last mount.

\section{Blood Sampling and Analysis}

Blood samples were collected via coccygeal venipuncture into Vacutainers (Becton Dickinson, Plymouth, UK) containing lithium heparin as an anticoagulant. Samples were centrifuged at $2,000 \times g$ for $15 \mathrm{~min}$ at $5^{\circ} \mathrm{C}$, plasma was decanted, and stored at $-20^{\circ} \mathrm{C}$ until further analysis. Concentrations of $\mathrm{P} 4$ in plasma were determined in samples taken from d 0 to 6 (at 8-h intervals) and from d 7 to ovulation (at 24-h intervals) using a commercially available solid-phase RIA (CoatA-Count Progesterone, Diagnostic Products Corp., Los Angeles, CA); the inter- and intraassay CV were 3.7 and $9.5 \%$, respectively. Circulating E2 and FSH concentrations were measured in samples collected on $\mathrm{d} 0$ to 6 (at 8-h intervals), and from d 15 until ovulation (at 8-h intervals). Concentrations of FSH were quantified using a validated RIA as described by Crowe et al. (1997); the inter- and intraassay CV were 7.4 and $12 \%$, respectively. Circulating concentrations of E2 were determined by RIA following an extraction step (Prendiville et al., 1995) using an Adaltis MAIA E2 kit (Biostat, Stockport, UK); the inter- and intraassay CV were 16.5 and $19.3 \%$, respectively.

Peak circulating P4 concentrations were calculated as the mean of the 4 greatest circulating $\mathrm{P} 4$ concentrations. The time when peak circulating $\mathrm{P} 4$ concentration occurred was determined as the mean of the 4 time points corresponding to the 4 greatest $\mathrm{P} 4$ concentration values. The day of luteolysis was determined as the day when circulating P4 concentration declined to $50 \%$ of peak and further declined to $25 \%$ of peak the following day. Circulating concentrations of E2 were graphed for each cow, and peak concentrations, day of peak, and the rate of increase from basal levels to peak were determined. For all hormone assays, each genotype was equally represented in each assay and all samples for a cow of a given genotype were completed in a single assay.

\section{Data Handling and Statistical Analysis}

All statistical analysis and data handling was carried out using SAS (SAS Institute Inc., Cary, NC), except that box plots were generated using $\mathrm{R}$ ( $\mathrm{R}$ Development Core Team, 2011). Data from cows with atypical estrous cycles were omitted if the variable in question was identified as an outlier for the particular genotype. Data were checked for normality. A Box-Cox transformation was used to normalize the distribution of $\mathrm{P} 4$, E2, and FSH data. Nontransformed P4, E2, and FSH data were used in Figures 2, 3, and 5 for illustrative purposes.

The effect of genotype on variables with repeated measures such as follicle and CL size measurements and blood hormone concentrations were determined using mixed models with cow nested within genotype as a random effect. A first-order autoregressive covariance structure with homogeneous variance provided the best fit for the database on Akaike's information criterion values. Transformed data were used to calculate $P$ values, and the estimated group means and $95 \%$ confidence intervals reported are back-transformed values. The effects of genotype, parity, day of cycle, calving date, and their interactions were included in the final model statements where significant $(P<0.1)$.

The effect of genotype on continuous variables without repeated measures such as day of first wave emergence, first-wave DF maximum diameter, the interval 

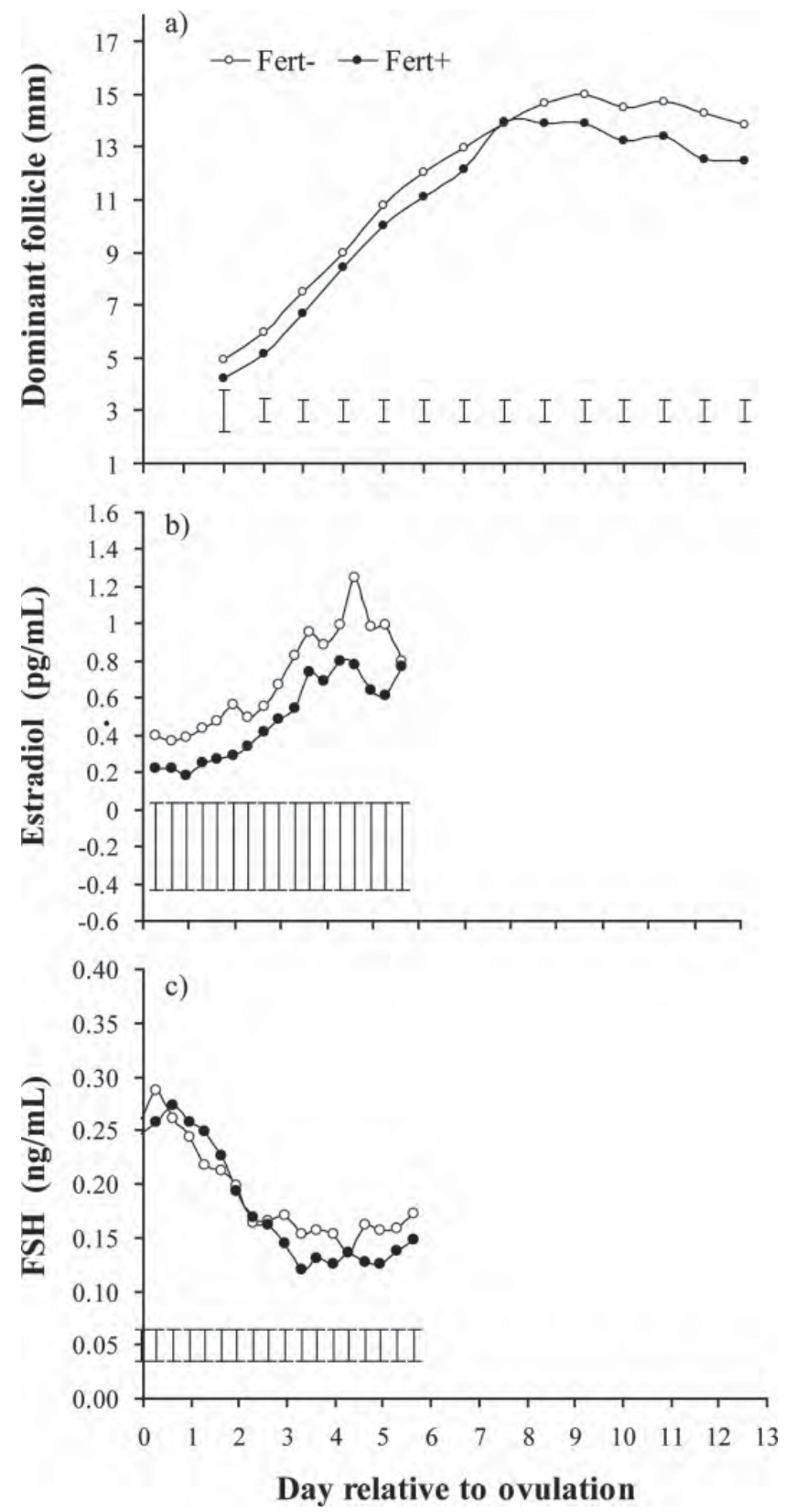

Figure 2. Dominant follicle size and circulating concentrations of estradiol (E2) and FSH during the first follicular wave in 19 Fert+ and 11 Fert- cows (i.e., with good or poor genetic merit for fertility traits, respectively). Vertical bars indicate the pooled standard error of the difference. Top panel: No genotype $(P=0.11)$, genotype $\times$ day of cycle, or genotype $\times$ parity effect was detected for first wave dominant follicle size $(\mathrm{SED}=0.59 \mathrm{~mm})$. Middle panel: No effect of genotype or genotype $\times$ parity interaction was observed for plasma E2 concentrations $(P>0.05)$. A significant genotype $\times$ day of cycle interaction $(P$ $<0.05$ ) was observed for E2 from $8 \mathrm{~h}$ before ovulation until d 6 of the cycle. The mean (95\% CI in parentheses) circulating E2 concentrations were $0.40(0.34,0.46)$ and $0.48(0.39,0.59)$ for Fert+ and Fertrespectively. Bottom panel: No genotype, genotype $\times$ day of cycle, or genotype $\times$ parity interaction effects were detected for plasma FSH concentrations $(P>0.005)$ from $1 \mathrm{~d}$ before ovulation until $\mathrm{d} 6$ of the cycle. The mean (95\% CI in parentheses) circulating FSH concentration were $0.17(0.15,0.18)$ and $0.18(0.16,0.20)$ for Fert+ and Fert-, respectively. from emergence of final wave to ovulation, interval from dominance to ovulation, and the ovulatory DF maximum diameter were determined using mixed models with cow nested within genotype as a random effect. The effect of genotype, parity, and the interaction between genotype and parity were tested; calving date was included as an adjustment variable, and significant effects $(P<0.1)$ were maintained in the final model.

Differences between genotypes for variables with a binomial distribution (the proportion of cows with 2 or $\geq 3$ follicular waves, the proportion that ovulated or failed to ovulate, and the proportion that exhibited or failed to exhibit estrus) were tested using the Fisher exact test. The effect of genotype on the number of follicular waves was analyzed using PROC NPAR1WAY and the Kruskal-Wallis test.

\section{RESULTS}

\section{General Characteristics of the Estrous Cycle}

The effects of genotype on ovarian measurements during the estrous cycle are summarized in Table 3. Genotype had a significant effect $(P=0.01)$ on cycle length; the interovulatory interval was $4.1 \pm 1.08 \mathrm{~d}$ shorter in Fert+ cows compared with Fert- cows. The Fert+ cows tended to have fewer $(P=0.065)$ follicular waves during the estrous cycle than Fert- cows (2.2 vs. 2.7 waves). We observed no effect of genotype on the proportion of cows with 2 or $\geq 3$ follicular waves $(P>$ $0.05)$. Estrous cycles with 2 follicular waves were most common in both Fert+ $(79 \%, 15 / 19$ cows $)$ and Fert(54\% 6/11 cows) cows. Genotype did not affect the mean daily number of follicles $<5 \mathrm{~mm}$ present on both ovaries during the first $13 \mathrm{~d}$ of the cycle (20.0 vs. 18.6 for Fert+ and Fert-, respectively). Of cows that successfully underwent luteolysis and developed a preovulatory follicle, a greater proportion $(P<0.01)$ of Fertcows failed to ovulate the DF (0 vs. $18 \%$ for Fert+ and Fert-, respectively). Of cows that successfully ovulated the preovulatory DF, a greater proportion $(P=0.02)$ of Fert- cows failed to demonstrate behavioral estrus ( 2 vs. $22 \%$ for Fert+ and Fert-, respectively). Of cows that showed behavioral estrus, a greater proportion $(P$ $=0.04$ ) of Fert - cows failed to ovulate a DF (0 vs. $14 \%$ for Fert+ and Fert-, respectively). Genotype did not affect the proportion of cows having multiple ovulations (2 vs. $7 \%$ for Fert+ and Fert-, respectively)

\section{First Follicular Wave}

The effect of genotype on follicular dynamics and circulating concentrations of FSH and E2 during the first follicle wave are summarized in Table 4. Cow 
Table 3. The effect of genetic merit for fertility traits [good (Fert+) or poor (Fert-)] on estrous cycle characteristics

\begin{tabular}{|c|c|c|c|c|}
\hline Variable & \multicolumn{2}{|c|}{ Genotype } & $\mathrm{SED}^{1}$ & $P$-value \\
\hline Animals (no.) & 18 & 10 & & \\
\hline Number of follicular waves (no.) & 2.2 & 2.7 & & 0.07 \\
\hline Proportion with 2 follicular waves (no.) & $0.79(15 / 19)$ & $0.54(6 / 11)$ & & 0.2 \\
\hline Proportion with $\geq 3$ follicular waves (no.) & $0.21(4 / 19)$ & $0.45(5 / 11)$ & & 0.2 \\
\hline Proportion that ovulated but failed to exhibit estrus ${ }^{2}$ & $0.02(1 / 41)$ & $0.22(5 / 23)$ & & 0.02 \\
\hline Proportion that exhibited estrus but failed to ovulate ${ }^{2}$ & $0(0 / 40)$ & $0.14(3 / 21)$ & & 0.04 \\
\hline Proportion with double ovulations ${ }^{2}$ & $0.02(1 / 41)$ & $0.07(2 / 28)$ & & 0.6 \\
\hline
\end{tabular}

${ }^{1} \mathrm{SED}=$ pooled standard error of the difference.

${ }^{2}$ Combined data from synchronized and spontaneous heat.
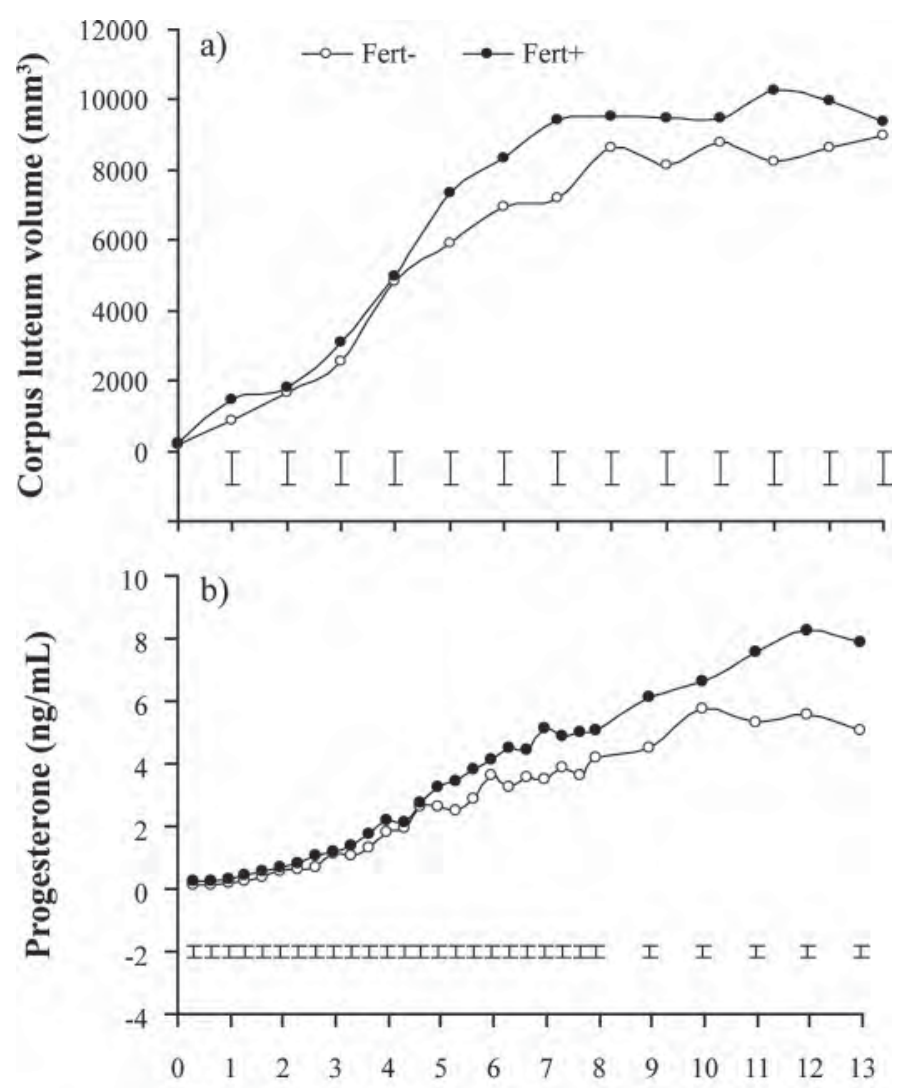

Day relative to ovulation

Figure 3. Corpus luteum (CL) volume and circulating concentrations of progesterone (P4) during the first $13 \mathrm{~d}$ of the cycle in 19 Fert+ and 11 Fert- cows (i.e., with good or poor genetic merit for fertility traits, respectively). Vertical bars indicate the pooled standard error of the difference. Top panel: CL volume tended to be larger in Fertcows $(P=0.08)$ during the first $13 \mathrm{~d}$ of the cycle. No genotype $\times$ day of cycle or genotype $\times$ parity interactions were observed for CL volume $(P>0.05)$. Bottom panel: Plasma $\mathrm{P} 4$ concentrations were significantly greater in Fert+ cows $(P<0.01)$ during the first $13 \mathrm{~d}$ of the cycle. No genotype $\times$ parity interaction was observed, but a significant genotype $\times$ day of cycle interaction existed $(P<0.001)$. genotype did not affect day of emergence, number of follicles $<5 \mathrm{~mm}$, or day of DF peak diameter (all $P>$ $0.05)$. Genotype did not affect $(P=0.11)$ the mean size of the DF during the first wave (Figure 2). However, the maximum diameter of the first-wave DF tended to be greater $(1.31 \pm 0.51 \mathrm{~mm})$ in Fert- compared with Fert $+\operatorname{cows}(P=0.08)$. Circulating concentrations of FSH during the first follicular wave were similar for both genotypes (Figure 2). Cow genotype did not affect peak FSH concentrations, day of peak FSH concentration, or the increase in FSH from basal concentrations to peak concentrations (all $P>0.05$ ). The Fert + cows took $18.1 \pm 9.1 \mathrm{~h}$ less $(P=0.05)$ to reach peak FSH concentrations than Fert- cows. We observed a significant genotype by day of cycle interaction $(P<0.05)$ for circulating E2 concentrations during the first follicular wave (Figure 2). Genotype did not affect peak E2 concentrations, day of peak E2 concentrations, or the interval from peak FSH concentrations to peak E2 concentrations (all $P>0.05$ ).

\section{Volume and P4 Concentration}

The effect of genotype on CL development and plasma concentrations of $\mathrm{P} 4$ during the first $13 \mathrm{~d}$ of the cycle are illustrated in Figure 3 and summarized in Table 5. During the first $13 \mathrm{~d}$ of the cycle, CL volume was $16 \%$ greater in Fert+ $(P=0.08)$ than in Fertcows. Circulating concentrations of $\mathrm{P} 4$ did not differ between Fert+ and Fert- cows during the first $5 \mathrm{~d}$ of the cycle (0.73 vs. $0.59 \mathrm{ng} / \mathrm{mL}$, respectively). From d 5 to 13 of the cycle, circulating concentrations of $\mathrm{P} 4$ were approximately $34 \%$ greater $(P<0.001)$ in Fert+ cows than in Fert- cows (5.15 vs. $3.84 \mathrm{ng} / \mathrm{mL}$, respectively); the Fert+ cows had greater peak plasma $\mathrm{P} 4$ concentrations $(P=0.02$; Figure 4 . The day of the cycle when peak plasma $\mathrm{P} 4$ concentrations occurred tended to be earlier $(P=0.09)$ in Fert + than in Fert- cows. Lute- 
Table 4. The effect of genetic merit for fertility traits [good (Fert+) or poor (Fert-)] on follicular measurements and circulating concentrations of estradiol (E2) and FSH during the first follicular wave

\begin{tabular}{|c|c|c|c|c|}
\hline \multirow[b]{2}{*}{ Variable } & \multicolumn{2}{|c|}{ Genotype } & \multirow[b]{2}{*}{$\mathrm{SED}^{1}$} & \multirow[b]{2}{*}{$P$-value } \\
\hline & Fert+ & Fert- & & \\
\hline Day of first wave emergence (d) & 0.97 & 1.70 & 0.62 & 0.2 \\
\hline Follicles $>5 \mathrm{~mm}$ in first wave (no.) & 2.71 & 2.96 & 0.34 & 0.5 \\
\hline Day of first wave $\mathrm{DF}^{2}$ peak diameter (d) & 7.73 & 8.55 & 0.67 & 0.2 \\
\hline First wave DF maximum diameter (mm) & 14.80 & 16.11 & 0.72 & 0.08 \\
\hline Duration of increase of FSH to peak (h) & 37.6 & 55.7 & 13.0 & 0.05 \\
\hline Increase in FSH from basal levels to peak (ng/mL) & 0.19 & 0.18 & 0.03 & 0.8 \\
\hline Interval from peak FSH to first wave DF maximum diameter (d) & 6.5 & 6.8 & 0.52 & 0.5 \\
\hline Day of peak E2 (d) & 4.6 & 4.7 & 0.63 & 0.8 \\
\hline Peak E2 concentration (pg/mL) & 1.54 & 1.31 & 0.21 & 0.3 \\
\hline Duration of increasing E2 to peak (h) & 55.5 & 59.1 & 13.23 & 0.07 \\
\hline Increase in $\mathrm{E} 2$ from basal levels to peak ( $\mathrm{pg} / \mathrm{mL})$ & 1.15 & 1.0 & 0.21 & 0.4 \\
\hline
\end{tabular}

${ }^{1} \mathrm{SED}=$ pooled standard error of the difference.

${ }^{2}$ Dominant follicle.

olysis occurred $2.9 \mathrm{~d}$ earlier $(P=0.03)$ in Fert + cows than in Fert- cows. The interval from luteolysis to ovulation was $1.0 \pm 0.34 \mathrm{~d}$ shorter $(P=0.08)$ in Fert+ compared with Fert- cows (Table 5).

\section{Preovulatory Follicle Wave}

Genotype had no effect $(P>0.05)$ on the pattern of growth of the preovulatory DF from emergence to ovulation (Figure 6), with the exception that Fert+ cows ovulated a larger diameter $(P=0.03)$ follicle than Fert- cows $(+1.14 \pm 0.36 \mathrm{~mm})$. Cow genotype had no effect $(P>0.05)$ on the number of follicles $<5 \mathrm{~mm}$, the interval from preovulatory follicle emergence to ovulation, or the interval from preovulatory follicle dominance to ovulation (Table 6). Circulating concentrations of E2 during the final follicular wave were similar $(P>0.05)$ for both genotypes (Figure 6). Cow genotype did not affect peak E2 concentrations, interval from peak E2 concentrations to ovulation, or the increase in E2 from basal to peak concentrations (all $P>0.05$ ).

\section{Estrus Behavior}

The effect of genotype on estrus behavior measurements is summarized in Table 7 . Peak activity occurred $5.7 \pm 2.2 \mathrm{~h}$ earlier $(P=0.07)$ and was $41 \%$ greater $(P<0.01)$ in Fert+ compared with Fert- cows. During the period from 30 to $12 \mathrm{~h}$ before ovulation, Fert+ cows had significantly greater $(P<0.05)$ mean activity count than Fert- cows. Genotype had no effect on the interval from first mount to ovulation or last mount to ovulation; however, the Fert+ group tended to have a longer $(P=0.08)$ overall duration of estrus than the Fert- group $(7.5 \pm 0.54 \mathrm{~h}$ and $5.9 \pm 0.76 \mathrm{~h}$, respectively). The number of mounts and the duration of each mount did not differ between genotypes.

\section{Production Variables}

Mean daily milk yield during the course of the estrous cycle did not differ $(P>0.05)$ between genotypes $(20.3 \pm 0.54 \mathrm{~kg} / \mathrm{d}$ and $19.5 \pm 0.62 \mathrm{~kg} / \mathrm{d}$ for the Fert+ and Fert- cows, respectively). Similarly, genotype had no effect $(P>0.05)$ on milk solids yield $(1.36 \pm 0.039$ $\mathrm{kg} / \mathrm{d}$ vs. $1.31 \pm 0.044 \mathrm{~kg} / \mathrm{d}$ for Fert + and Fert- cows, respectively). The Fert+ cows tended to have greater BCS $(P=0.09)$ throughout the estrous cycle $(2.96 \pm$ 0.032 vs. $2.87 \pm 0.036$ units for Fert+ and Fert- cows, respectively).

\section{DISCUSSION}

This study provides compelling evidence that genetic merit for fertility traits has profound effects on the estrous cycle that are manifest in changes in ovarian follicle and CL measurements, circulating hormone concentrations, and estrus behavior. In the current study, factors known to affect ovarian function were similar in both experimental groups (age, nutrition, stage of lactation, phenotypic milk yield, genetic merit for milk production, proportion of Holstein genetics), but the animals were extremely divergent in genetic 
Table 5. The effect of genetic merit for fertility traits [good (Fert+) or poor (Fert-)] on circulating progesterone (P4) concentrations, timing of luteolysis, and interval from luteolysis to ovulation

\begin{tabular}{lccc}
\hline & \multicolumn{2}{c}{ Genotype } & \\
\cline { 2 - 3 } Variable & Fert & Fert- & SED \\
\hline Animals (no.) & 19 & 11 & \\
Day of cycle at peak P4 (d) & 12.3 & 14.7 & 1.34 \\
Peak P4 (ng/mL) & $8.07(7.25,8.96)$ & $6.5(5.59,7.55)$ & 0.09 \\
Interval from peak P4 to ovulation & 8.2 & 10.8 & 0.02 \\
Day of cycle at luteolysis & 16.5 & 19.4 & 0.76 \\
Interval from luteolysis to ovulation & 4.3 & 5.3 & 0.002 \\
\hline
\end{tabular}

${ }^{1} \mathrm{SED}=$ pooled standard error of the difference.

${ }^{2} \mathrm{CI}$ in parentheses.

merit for fertility traits. Thus, this animal model can be used to help elucidate the physiological mechanisms responsible for subfertility in lactating Holstein cows in a pasture-based production system.

The present study indicated that genetic merit for fertility traits alters the length of the estrous cycle. Compared with Fert+ cows, Fert- cows took approximately $3 \mathrm{~d}$ longer to undergo spontaneous luteolysis and approximately $5 \mathrm{~d}$ longer to achieve a spontane- ous ovulation in a natural cycle timed from a previous synchronized ovulation. Consensus is lacking between studies comparing estrous cycles in heifers and lactating cows with regard to the association between cycle length and fertility; some found shorter cycle lengths in heifers (Wolfenson et al., 2004), whereas others found no difference in cycle length (Sartori et al., 2004). In accordance with previous reports, cows in the current study predominantly had 2 waves of follicular development

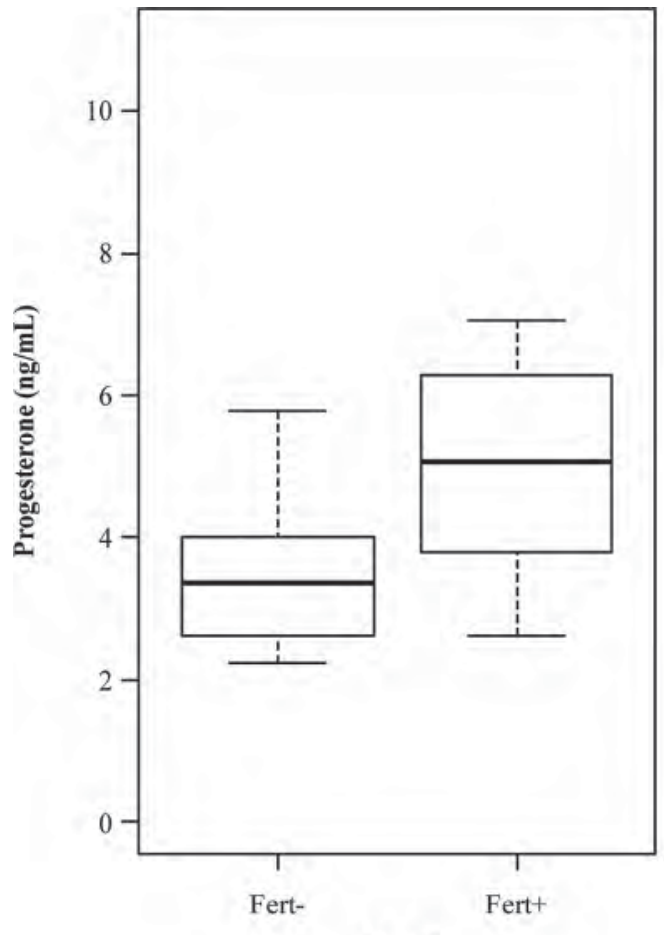

Day 7

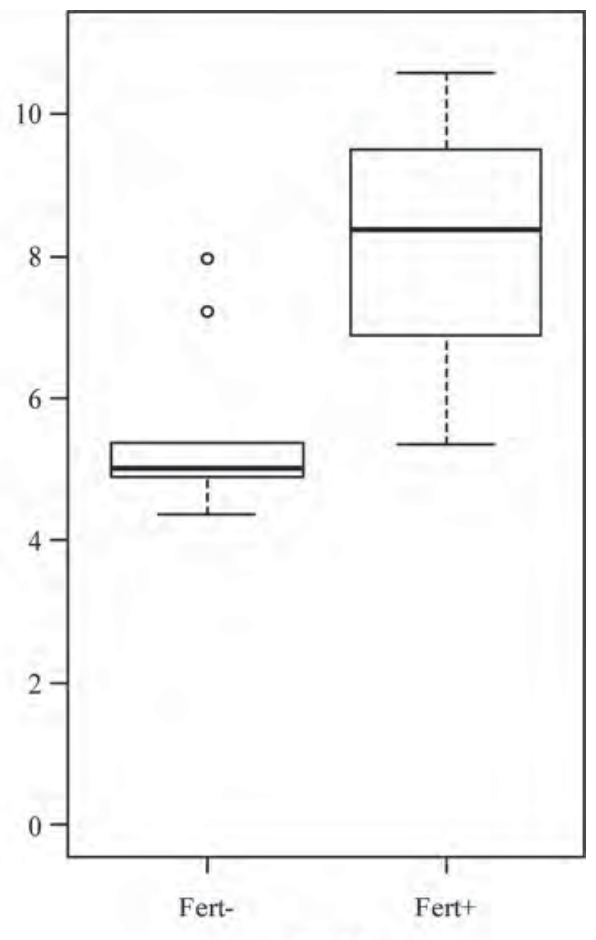

Day 12

Figure 4. Box plots depicting circulating concentrations of progesterone (P4) during d 7 and 12 of the estrous cycle in 19 Fert+ and 11 Fertcows (i.e., with good or poor genetic merit for fertility traits, respectively). Plasma $\mathrm{P} 4$ concentrations were significantly greater $(P<0.001)$ in Fert+ cows on both d 7 and d 12 of the cycle. The mean (95\% CI in parentheses) circulating P4 concentrations on d 7 were $5.00 \mathrm{ng} / \mathrm{mL}$ (4.33, $5.70)$ and $3.25 \mathrm{ng} / \mathrm{mL}(2.65,3.96)$ for Fert+ and Fert-, respectively. The mean (95\% CI in parentheses) circulating P4 concentrations on d 12 were $8.01 \mathrm{ng} / \mathrm{mL}(7.22,8.86)$ and $5.40 \mathrm{ng} / \mathrm{mL}(4.65,6.23)$ for Fert+ and Fert-, respectively. 

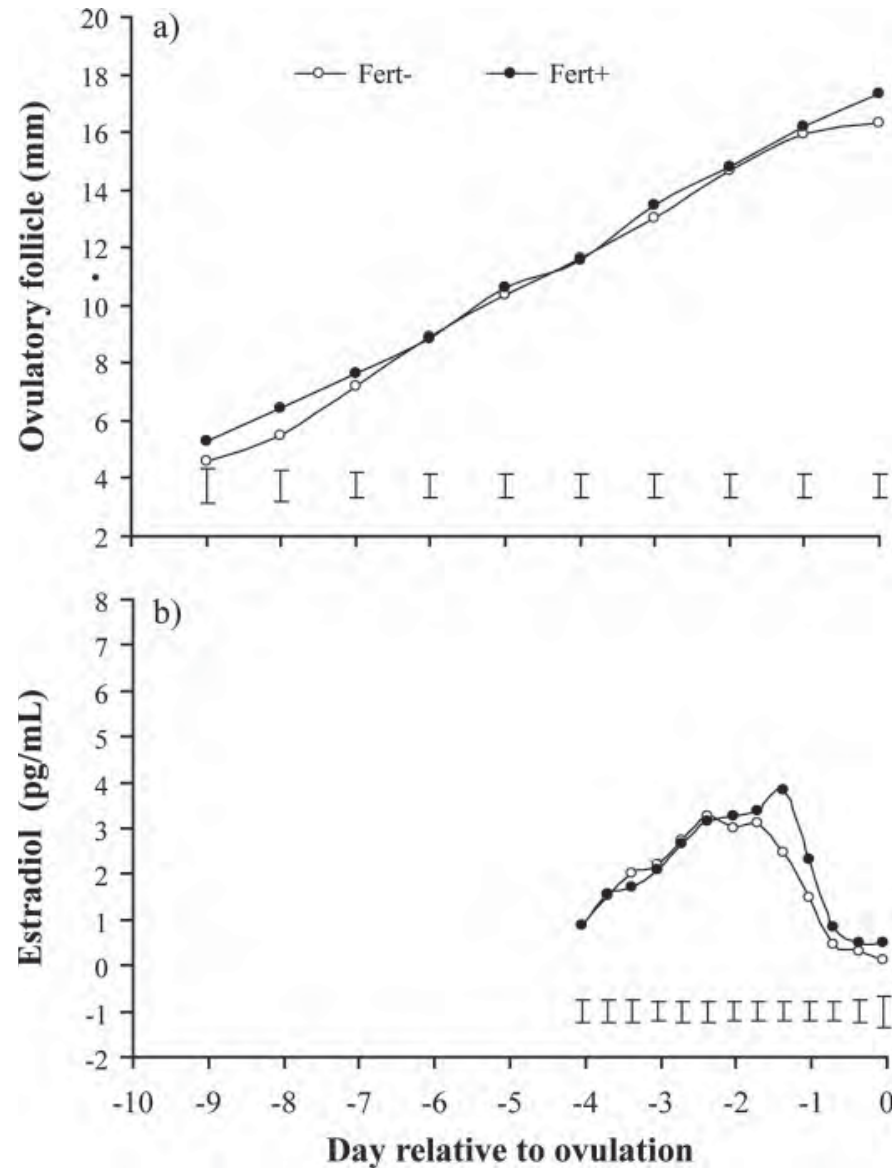

Figure 5. Preovulatory follicle growth and circulating concentrations of estradiol (E2) before ovulation in 18 Fert+ and 10 Fert- cows (i.e., with good or poor genetic merit for fertility traits, respectively). Vertical bars indicate the pooled standard error of the difference. Top panel: No effect of genotype, genotype $x$ day of cycle, or genotype $\times$ parity interaction was observed for preovulatory follicle diameter $(P>$ $0.05)$. Bottom panel: No effect of genotype, genotype $\times$ day of cycle, or genotype $\times$ parity interaction was observed for plasma estradiol concentration $(P>0.05)$.

(Townson et al., 2002; Bleach et al., 2004). Townson et al. (2002) reported superior reproductive performance in cows with 3 follicular waves compared with cows with 2 follicular waves. The current study does not support that finding, as Fert+ cows tended to have fewer follicular waves than Fert- cows. A prolonged period of preovulatory follicle dominance in cows with 2 follicular waves was suggested by Townson et al. (2002) as a potential cause for decreased fertility performance. In the current study, no difference between genotypes was observed in the duration of dominance of the preovulatory follicle.

Following the preovulatory LH surge, theca and granulosa cells of the DF undergo luteinization. This involves a series of biochemical and morphological changes that alter the steroidogenic pathway of both cell

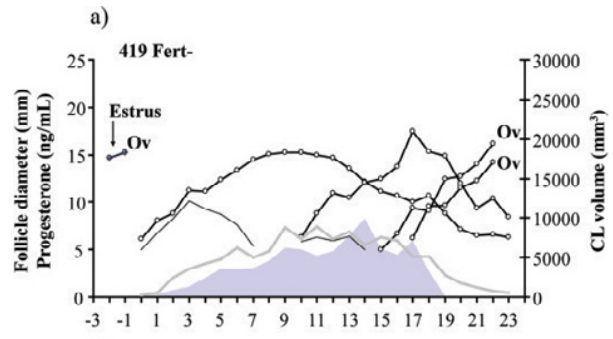

b)

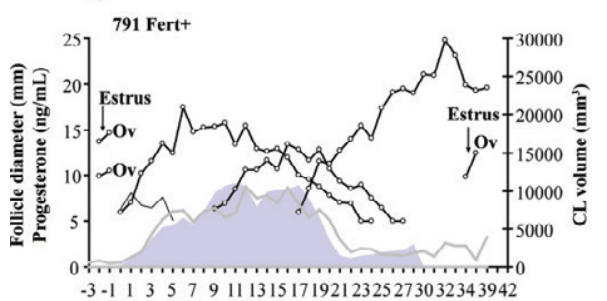

c)
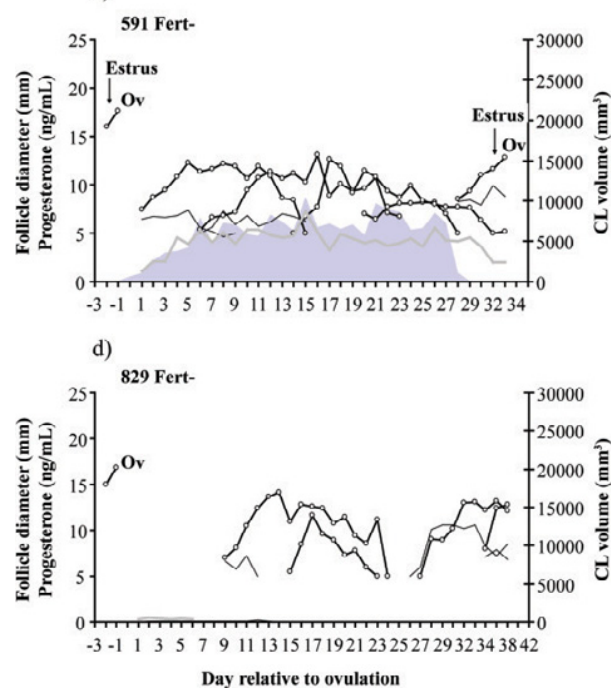

Figure 6. Patterns of follicular development (black lines: dominant follicle $=$ thick lines with open circles; subordinate follicles $=$ thin lines), luteal volume (dark gray line), and serum progesterone concentrations (light gray area) in cows with atypical estrous cycles. (A) A Fert- cow that ovulated a dominant follicle following behavioral estrus at the synchronized estrus, which resulted in formation of a functional corpus luteum (CL). Following luteolysis, 2 co-dominant follicles from the third follicular wave ovulated at a silent estrus. (B) A Fert + cow that ovulated 2 co-dominant follicles following behavioral estrus at the synchronized estrus, which resulted in the formation of 2 functional CL. One CL underwent structural and functional luteolysis between d 19 and 20, but the second CL did not undergo luteolysis until approximately $14 \mathrm{~d}$ later. Following luteolysis of the second CL, the growing dominant follicle of the third follicular wave failed to ovulate and continued to grow, forming a large persistent follicle. A fourth follicular wave emerged and the dominant follicle ovulated following behavioral estrus on d 39 of the cycle. (C) A Fert- cow that ovulated a dominant follicle following behavioral estrus at the synchronized estrus and formed a functional CL. Luteolysis did not occur until d 28. The dominant follicle of the fifth follicular wave ovulated following behavioral estrus on d 34 of the cycle. (D) A Fert- cow that ovulated a dominant follicle at the synchronized estrus without behavioral estrus. The newly ovulated follicle failed to develop into a functional CL. The cow became anestrous and turned over 4 anovulatory follicular waves. Ultrasound scanning ceased on d 38. Color version available in the online PDF. 
Table 6. The effect of genetic merit for fertility traits [good (Fert+) or poor (Fert-)] on follicle measurements, circulating concentrations of estradiol (E2) during the preovulatory follicle wave, and interval from peak E2 to peak estrus activity

\begin{tabular}{|c|c|c|c|c|}
\hline Variable & \multicolumn{2}{|c|}{ Genotype } & $\mathrm{SED}^{1}$ & $P$-value \\
\hline Follicles $>5 \mathrm{~mm}$ in ovulatory wave (no.) & 2.72 & 2.73 & 0.48 & 0.9 \\
\hline Interval from emergence to ovulation (d) & 9.62 & 9.06 & 0.60 & 0.3 \\
\hline Interval from dominance to ovulation (d) & 6.29 & 5.75 & 0.6 & 0.4 \\
\hline Ovulatory $\mathrm{DF}^{2}$ maximum diameter (mm) & 17.91 & 16.76 & 0.52 & 0.03 \\
\hline Peak E2 concentration (pg/mL) & 4.48 & 3.75 & 0.46 & 0.13 \\
\hline Duration of increasing E2 to peak (h) & 42 & 45 & 7.1 & 0.7 \\
\hline Increase in $\mathrm{E} 2$ from basal levels to peak $(\mathrm{pg} / \mathrm{mL})$ & 2.80 & 2.39 & 0.52 & 0.4 \\
\hline Interval from peak E2 to peak activity (h) & 2.6 & 9.9 & 6.87 & 0.3 \\
\hline
\end{tabular}

${ }^{1} \mathrm{SED}=$ pooled standard error of the difference.

${ }^{2}$ Dominant follicle.

types to synthesize P4 and thus form a CL (Niswender et al., 2000). The development of a functional CL and the timely increase in circulating concentrations of $\mathrm{P} 4$ play a crucial role in stimulating endometrial secretions necessary for embryonic growth and development (Garrett et al., 1988; Sreenan et al., 2001). It has been suggested that the reproductive failure of high-producing dairy cows is partially caused by a delayed postovulatory increase in circulating $\mathrm{P} 4$ concentrations and inadequate circulating $\mathrm{P} 4$ concentrations during the luteal phase (Mann and Lamming, 2001). Elevated plasma P4 concentrations are necessary for essential processes involved in embryo development, including maternal recognition of pregnancy (Mann and Lamming, 2001), functional changes in histotroph composition (Green et al., 2005), and structural changes in endometrial glandular duct density (Wang et al., 2007). In the current study, genetic merit for fertility traits had a significant effect on circulating P4 concentrations. As early as d 5 of the cycle, Fert+ cows had greater plasma P4 con- centrations, and this difference was maintained until luteolysis (25\% greater P4 plasma concentration). The essential role of circulating $\mathrm{P} 4$ concentrations for reproductive performance is well documented (Stronge et al., 2005; Lopes et al., 2007; Clemente et al., 2009). Studies comparing the estrous cycles of heifers and lactating cows found increased circulating $\mathrm{P} 4$ concentrations in heifers as early as d 3 (Wolfenson et al., 2004) and d 6 (Sartori et al., 2004) of the cycle.

Increased steroid metabolism has been suggested as a potential mechanism responsible for the reduced circulating P4 concentrations in lactating cows (Sangsritavong et al., 2002). In the current study, we observed no difference in the size of the follicle that ovulated at the synchronized estrus. Following ovulation, however, Fert+ cows developed a CL that was $16 \%$ larger than that in Fert- cows. If we assume that the steroid production capacity per unit volume of CL is similar between genotypes, the observed differences in circulating $\mathrm{P} 4$ concentrations $(+25 \%)$ can only partially be

Table 7. The effect of genetic merit $[\operatorname{good}($ Fert+) or poor (Fert-)] for fertility traits on estrus behavior (SED)

\begin{tabular}{|c|c|c|c|c|}
\hline Variable & \multicolumn{2}{|c|}{ Genotype } & $\mathrm{SED}^{1}$ & $P$-value \\
\hline Interval from peak activity to ovulation (h) & 32.8 & 27.1 & 3.16 & 0.065 \\
\hline Peak activity (counts) & 168.5 & 119.7 & 15.98 & 0.005 \\
\hline Activity $12-30 \mathrm{~h}$ before ovulation & 103.4 & 73.3 & 13.4 & 0.03 \\
\hline Interval from first mount to ovulation (h) & 35.6 & 37.0 & 2.12 & 0.5 \\
\hline Mounts $^{2}$ (no.) & 12.1 & 12.8 & 2.50 & 0.6 \\
\hline Duration of all mounts ${ }^{2}(\mathrm{~s})$ & 20.7 & 20.8 & 4.90 & 0.9 \\
\hline
\end{tabular}

${ }^{1} \mathrm{SED}=$ pooled standard error of the difference.

${ }^{2}$ Combined data from synchronized and spontaneous estrus (Fert $+\mathrm{n}=40$; Fert $-\mathrm{n}=21$ ). 
explained by the larger CL volume of the Fert+ cows. This suggests that other factors, such as the abundance of steroidogenic substrates, intracellular steroidogenic pathways, luteal vascularization, and metabolic clearance rate (Wiltbank et al., 2006), may be involved in the observed differences in circulating $\mathrm{P} 4$ concentration. As no differences between genotypes were observed in daily milk yield and DMI (Cummins et al., 2012), liver blood flow and steroid metabolic clearance rate would be expected to be similar. Although the current study established that genetic merit for fertility traits affects circulating P4 concentrations, the etiology of increased circulating P4 concentrations and the mechanisms by which this is translated into superior reproductive performance warrant further investigation.

The ovarian DF is central to reproductive biology, playing a crucial role in most processes from primordial follicle development to successful maintenance of pregnancy (Lucy, 2007). In the current study, genotype had a significant effect on ovulatory follicle diameter, with Fert+ cows ovulating a larger DF. This finding is in agreement with studies that found a positive association between ovulatory follicle size and pregnancy rate in beef (Perry et al., 2005) and dairy cows (Vasconcelos et al., 2001; Lopes et al., 2007). The differences in ovulatory follicle diameter in the present study were not associated with differences in circulating E2 concentrations. This is probably because the DF in the final follicular wave was similar in size during the process of selection and dominance and only deviated in size on the last day of the cycle. A notable feature of the current study was the large proportion (14\%) of Fertcows that underwent luteolysis and showed behavioral estrus but failed to ovulate the DF. This suggests that either the LH surge in these animals was inadequate to cause ovulation or the ovarian response to a normal LH surge was dysfunctional. Details of the duration and magnitude of the LH surge were not determined in the current study. Similar levels of ovulation failure (3.4 to $14.1 \%$ ) have been reported in studies by López-Gatius et al. (2005) and Demetrio et al. (2007) in high-yielding Holstein cows. Heat stress was cited as a potential cause for such high levels of ovulation failure (López-Gatius et al., 2005). In the current study, however, mean daily air temperatures ranged from $8.9^{\circ} \mathrm{C}$ to $18.8^{\circ} \mathrm{C}$, indicating that heat stress was not a contributing factor in Fert- cows that failed to ovulate. In addition, milk production was similar in Fert+ and Fert- cows and was low compared with that in animals in TMR systems. Thus, level of milk production per se can be eliminated as a causative factor responsible for ovulation failure in the current study.

A cow's ability to show behavioral estrus and successfully ovulate a DF is a prerequisite for optimal timing of AI and subsequent oocyte fertilization. The reduction in both the intensity and duration of estrus is a major contributing factor to the decline in reproductive efficiency in the modern dairy cow (Dobson et al., 2008; Law et al., 2009). Of cows that displayed standing heat in the current study, estrus behavior differences between genotypes were minor. Of the cows that successfully ovulated, however, $22 \%$ of Fert-cows recorded no standing mounts compared with only $2 \%$ of Fert+ cows. Moreover, Fert+ cows recorded $41 \%$ greater peak activity at estrus than Fert-cows. These disparities highlight for the first time the role that genetic merit for fertility traits has on estrus behavior. The performance of the Fert- cows is consistent with a previous study on high-yielding Holstein cows ( $\mathrm{n}=$ 463 ), which reported that $>30 \%$ of ovulations occurred without any display of standing heat (Lopez et al., 2004). That study demonstrated that estrus behavior was correlated with level of milk production (negative) and circulating E2 concentrations (positive). In the current study, however, both milk yield and circulating E2 concentrations were similar between genotypes. The exact underlying processes whereby genetic merit for fertility traits alters estrus behavior remains unknown. Potential differences between genotypes could exist in the threshold concentrations of E2 required for estrus and the LH surge to occur, as has been documented between species (Fabre-Nys et al., 1993). Differences in luteal-phase P4 priming of the neural mechanisms involved in $\mathrm{GnRH}$ release, as observed in sheep (Skinner et al., 2000), could also explain some of the variation.

\section{CONCLUSIONS}

Genetic merit for fertility traits had a significant effect on characteristics of the estrous cycle and was independent of management, plane of nutrition, stage of lactation, proportion of Holstein ancestry, and genotypic and phenotypic milk yield. The Fert+ group had shorter estrous cycles and greater circulating P4 concentrations, and they exhibited stronger estrus and ovulated larger follicles than the Fert- group. The differences in follicular dynamics and steroid concentrations may partially explain the superior fertility performance of the Fert+ cows. These results highlight the effect of genetic merit for fertility traits on measurable changes in ovarian function.

\section{ACKNOWLEDGMENTS}

The authors thank J. P. Murphy, J. Kenneally, and the Moorepark farm staff for management and care of the animals. We also thank P. Furney (University College Dublin, Ireland) for her technical assistance. 
The Teagasc Walsh Fellowship scheme, National Development Plan, and Dairy Levy funding are gratefully acknowledged.

\section{REFERENCES}

Bleach, E. C. L., R. G. Glencross, and P. G. Knight. 2004. Association between ovarian follicle development and pregnancy rates in dairy cows undergoing spontaneous oestrous cycles. Reproduction 127:621-629.

Butler, W. R., and R. D. Smith. 1989. Interrelationships between energy balance and postpartum reproductive function in dairy cattle. J. Dairy Sci. 72:767-783.

Clemente, M., J. de La Fuente, T. Fair, A. Al Naib, A. Gutierrez-Adan, J. F. Roche, D. Rizos, and P. Lonergan. 2009. Progesterone and conceptus elongation in cattle: A direct effect on the embryo or an indirect effect via the endometrium? Reproduction 138:507-517.

Crowe, M. A., V. Padmanabhan, N. Hynes, S. J. Sunderland, W. J. Enright, I. Z. Beitins, and J. F. Roche. 1997. Validation of a sensitive radioimmunoassay to measure serum follicle-stimulating hormone in cattle: Correlation with biological activity. Anim. Reprod. Sci. 48:123-136.

Cummins, S. B., P. Lonergan, A. C. O. Evans, D. P. Berry, R. D. Evans, and S. T. Butler. 2012. Genetic merit for fertility traits in Holstein cows: I. Production characteristics and reproductive efficiency in a pasture-based system. J. Dairy Sci. 95:1310-1322.

De la Sota, R. L., M. C. Lucy, C. R. Staples, and W. W. Thatcher. 1993. Effects of recombinant bovine somatotropin (Sometribove) on ovarian function in lactating and nonlactating dairy cows. J. Dairy Sci. 76:1002-1013.

Demetrio, D. G. B., R. M. Santos, C. G. B. Demetrio, and J. L. M. Vasconcelos. 2007. Factors affecting conception rates following artificial insemination or embryo transfer in lactating Holstein cows. J. Dairy Sci. 90:5073-5082.

Dobson, H., S. L. Walker, M. J. Morris, J. E. Routly, and R. F. Smith. 2008. Why is it getting more difficult to successfully artificially inseminate dairy cows? Animal 2:1104-1111.

Dransfield, M. B. G., R. L. Nebel, R. E. Pearson, and L. D. Warnick. 1998. Timing of insemination for dairy cows identified in estrus by a radiotelemetric estrus detection system. J. Dairy Sci. 81:1874-1882.

Evans, R. D., P. Dillon, F. Buckle, D. P. Berry, M. Wallace, V. Ducrocq, and D. J. Garrick. 2006. Trends in milk production, calving rate and survival of cows in 14 Irish dairy herds as a result of the introgression of Holstein-Friesian genes. Anim. Sci. 82:423-433.

Fabre-Nys, C., G. B. Martin, and G. Venier. 1993. Analysis of the hormonal control of female sexual behavior and the preovulatory LH surge in the ewe: Roles of quantity of estradiol and duration of its presence. Horm. Behav. 27:108-121.

Garrett, J. E., R. D. Geisert, M. T. Zavy, and G. L. Morgan. 1988. Evidence for maternal regulation of early conceptus growth and development in beef cattle. J. Reprod. Fertil. 84:437-446.

Ginther, O. J., K. Kot, L. J. Kulick, and M. C. Wiltbank. 1997. Emergence and deviation of follicles during the development of follicular waves in cattle. Theriogenology 48:75-87.

Green, M. P., M. G. Hunter, and G. E. Mann. 2005. Relationships between maternal hormone secretion and embryo development on day 5 of pregnancy in dairy cows. Anim. Reprod. Sci. 88:179-189.

Hickey, M. C., P. French, and J. Grant. 2003. Out-wintering pads for finishing beef cattle: Animal production and welfare. Anim. Sci. $75: 447-458$.

Law, R. A., F. J. Young, D. C. Patterson, D. J. Kilpatrick, A. R. G. Wylie, and C. S. Mayne. 2009. Effect of dietary protein content on estrous behavior of dairy cows during early and mid lactation. J. Dairy Sci. 92:1013-1022.

Lopes, A. S., S. T. Butler, R. O. Gilbert, and W. R. Butler. 2007. Relationship of pre-ovulatory follicle size, estradiol concentrations and season to pregnancy outcome in dairy cows. Anim. Reprod. Sci. 99:34-43.
Lopez, H., L. D. Satter, and M. C. Wiltbank. 2004. Relationship between level of milk production and estrous behavior of lactating dairy cows. Anim. Reprod. Sci. 81:209-223.

López-Gatius, F., M. López-Béjar, M. Fenech, and R. H. F. Hunter. 2005. Ovulation failure and double ovulation in dairy cattle: Risk factors and effects. Theriogenology 63:1298-1307.

Lucy, M. C. 2007. The bovine dominant ovarian follicle. J. Anim. Sci. 85(E. Suppl.):E89-E99.

Lucy, M. C., and B. A. Crooker. 2001. Physiological and genetic differences between low and high index cows. Pages 223-236 in Fertility in the High-Producing Dairy Cow. Br. Soc. Anim. Sci. Occ. Publ. No. 26, Br. Soc. Anim. Sci., Galway, Ireland.

Mann, G. E., and G. E. Lamming. 2001. Relationship between maternal endocrine environment, early embryo development and inhibition of the luteolytic mechanism in cows. Reproduction 121:175-180.

Niswender, G. D., J. L. Juengel, P. J. Silva, M. K. Rollyson, and E. W. McIntush. 2000. Mechanisms controlling the function and life span of the corpus luteum. Physiol. Rev. 80:1-29.

Perry, G. A., M. F. Smith, M. C. Lucy, J. A. Green, T. E. Parks, M. D. MacNeil, A. J. Roberts, and T. W. Geary. 2005. Relationship between follicle size at insemination and pregnancy success. Proc. Natl. Acad. Sci. USA 102:5268-5273.

Prendiville, D. J., W. J. Enright, M. A. Crowe, M. Finnerty, N. Hynes, and J. F. Roche. 1995. Immunization of heifers against gonadotropin-releasing hormone: Antibody titers, ovarian function, body growth, and carcass characteristics. J. Anim. Sci. 73:2382-2389.

Pursley, J. R., M. C. Wiltbank, J. S. Stevenson, J. S. Ottobre, H. A. Garverick, and L. L. Anderson. 1997. Pregnancy rates per artificial insemination for cows and heifers inseminated at a synchronized ovulation or synchronized estrus. J. Dairy Sci. 80:295-300.

R Development Core Team. 2011. R: A language and environment for statistical computing. R Foundation for Statistical Computing, Vienna, Austria. http://www.R-project.org/.

Robinson, R. S., A. J. Hammond, D. C. Wathes, M. G. Hunter, and G. E. Mann. 2008. Corpus luteum- endometrium-embryo interactions in the dairy cow: Underlying mechanisms and clinical relevance. Reprod. Domest. Anim. 43(Suppl. 2):104-112.

Royal, M. D., A. O. Darwash, A. P. F. Flint, R. Webb, J. A. Woolliams, and G. E. Lamming. 2000. Declining fertility in dairy cattle: Changes in traditional and endocrine parameters of fertility. Anim. Sci. 70:487-501.

Sangsritavong, S., D. K. Combs, R. Sartori, L. E. Armentano, and M. C. Wiltbank. 2002. High feed intake increases liver blood flow and metabolism of progesterone and estradiol-17 $\beta$ in dairy cattle. J. Dairy Sci. 85:2831-2842.

Sartori, R., J. Haughian, G. J. M. Rosa, R. D. Shaver, and M. C. Wiltbank. 2000. Differences between lactating cows and nulliparous heifers in follicular dynamics, luteal growth, and serum steroid concentrations. J. Dairy Sci. 83(Suppl. 1):212. (Abstr.)

Sartori, R., J. M. Haughian, R. D. Shaver, G. J. M. Rosa, and M. C. Wiltbank. 2004. Comparison of ovarian function and circulating steroids in estrous cycles of Holstein heifers and lactating cows. J. Dairy Sci. 87:905-920.

Sartori, R., R. Sartor-Bergfelt, S. A. Mertens, J. N. Guenther, J. J. Parrish, and M. C. Wiltbank. 2002. Fertilization and early embryonic development in heifers and lactating cows in summer and lactating and dry cows in winter. J. Dairy Sci. 85:2803-2812.

Skinner, D. C., T. G. Harris, and N. P. Evans. 2000. Duration and amplitude of the luteal phase progesterone increment times the estradiol-induced luteinizing hormone surge in ewes. Biol. Reprod. 63:1135-1142.

Sreenan, J. M., M. G. Diskin, and D. G. Morris. 2001. Embryo survival rate in cattle: A major limitation to the achievement of high fertility. Pages 93-104 in Br. Soc. Anim. Sci. Occ. Publ. No. 26. Br. Soc. Anim. Sci., Galway, Ireland.

Stronge, A. J. H., J. M. Sreenan, M. G. Diskin, J. F. Mee, D. A. Kenny, and D. G. Morris. 2005. Post-insemination milk progesterone concentration and embryo survival in dairy cows. Theriogenology 64:1212-1224. 
Townson, D. H., P. C. Tsang, W. R. Butler, M. Frajblat, L. C. Griel, C. J. Johnson, R. A. Milvae, G. M. Niksic, and J. L. Pate. 2002. Relationship of fertility to ovarian follicular waves before breeding in dairy cows. J. Anim. Sci. 80:1053-1058.

Vasconcelos, J. L. M., R. Sartori, H. N. Oliveira, J. G. Guenther, and M. C. Wiltbank. 2001. Reduction in size of the ovulatory follicle reduces subsequent luteal size and pregnancy rate. Theriogenology 56:307-314.

Wang, C. K., R. S. Robinson, A. P. F. Flint, and G. E. Mann. 2007. Quantitative analysis of changes in endometrial gland morphology during the bovine oestrous cycle and their association with progesterone levels. Reproduction 134:365-371.

Washburn, S. P., W. J. Silvia, C. H. Brown, B. T. McDaniel, and A. J. McAllister. 2002. Trends in reproductive performance in southeastern Holstein and Jersey DHI herds. J. Dairy Sci. 85:244-251.
Wiltbank, M., H. Lopez, R. Sartori, S. Sangsritavong, and A. Gümen. 2006. Changes in reproductive physiology of lactating dairy cows due to elevated steroid metabolism. Theriogenology 65:17-29.

Wiltbank, M. C., A. Gümen, and R. Sartori. 2002. Physiological classification of anovulatory conditions in cattle. Theriogenology $57: 21-52$.

Wiltbank, M. C., R. Sartori, S. Sangsritavong, H. Lopez, J. M. Haughian, P. M. Fricke, and A. Gumen. 2001. Novel effects of nutrition on reproduction in lactating dairy cows. J. Dairy Sci. 84(Suppl. 1):32.

Wolfenson, D., G. Inbar, Z. Roth, M. Kaim, A. Bloch, and R. BrawTal. 2004. Follicular dynamics and concentrations of steroids and gonadotropins in lactating cows and nulliparous heifers. Theriogenology 62:1042-1055. 